\title{
Psychostimulant-Induced Plasticity of Intrinsic Neuronal Excitability in Ventral Subiculum
}

\author{
Donald C. Cooper, Shannon J. Moore, Nathan P. Staff, and Nelson Spruston \\ Department of Neurobiology and Physiology, Institute for Neuroscience, Northwestern University, Evanston, Illinois 60208
}

\begin{abstract}
Psychostimulant drugs such as amphetamine are prescribed to increase vigilance, suppress appetite, and treat attention disorders, but they powerfully activate the dopamine system and have serious abuse potential. Repeated psychostimulant exposure induces neuronal plasticity within the mesolimbic dopamine system. Here we present evidence that repeated amphetamine exposure results in a suppression of intrinsic neuronal excitability in the ventral subiculum, a hippocampal region that activates dopamine neurotransmission. We used patch-clamp recordings from brain slices obtained at different times after withdrawal from repeated amphetamine exposure to determine the long-term effects of amphetamine on subicular excitability. Using several postsynaptic indices of sodium channel function, our results show that excitability is decreased for days, but not weeks, after repeated amphetamine exposure. The resulting increase in action potential threshold and decrease in postsynaptic amplification of excitatory synaptic input provide the first direct evidence that psychostimulants induce plasticity of hippocampal output and suggest one mechanism by which drug withdrawal may influence limbic dopaminedependent learning and memory.
\end{abstract}

Key words: addiction; synaptic integration; hippocampus; reward system; dopamine; behavioral sensitization; bursting; learning; memory; mesolimbic; schizophrenia; spike timing-dependent plasticity

\section{Introduction}

Enhanced dopamine signaling resulting from repeated exposure to psychostimulants produces enduring addiction-associated neuroadaptations within the mesocorticolimbic dopamine system (White and Kalivas, 1998; Hyman and Malenka, 2001). The ventral subiculum (vSUB) is an important component within this system, providing the major source of output from the hippocampus to cortical and subcortical regions (Swanson and Cowan, 1977). Subiculum contains both regular spiking and intrinsically bursting neurons that code for spatial orientation (place cells), reward-directed navigation, memory retrieval, and delay activity associated with working memory (Sharp and Green, 1994; Gabrieli et al., 1997; Martin, 2001; Hampson et al., 2000; Martin and Ono, 2000; Zeineh et al., 2003).

Processed hippocampal information from the vSUB is distributed, via the fornix, to the prefrontal cortex (PFC) and nucleus accumbens (NAc), both prominent components of the dopamine system (Swanson, 1981; Lopes da Silva et al., 1984). Excitatory vSUB outputs play an especially critical role in controlling the excitability of NAc medium spiny neurons (O'Donnell and Grace, 1995), the activation of which by vSUB enhances dopamine neurotransmission via polysynaptic projections to mid-

Received July 5, 2003; revised Aug. 8, 2003; accepted Sept. 4, 2003.

This work was supported by grants from National Science Foundation (IBN-9876032 to N.S.), National Institute of Neurological Disorders and Stroke (NS-35180 to N.S.), National Institute on Drug Abuse (F32 DA 06089 to D.C.C.; F30 DA 14206 to N.P.S.), and National Institute of Mental Health (TG MH 067564 to S.J.M.). We thank Marina Wolf for suggestions regarding the amphetamine sensitization regimen, and Alexia Metz, Tim Jarsky, and Zayd Kahliq for assistance with amphetamine-induced stereotypy assessments.

Correspondence should be addressed to Nelson Spruston, Department of Neurobiology and Physiology, Northwestern University, 2205 Tech Drive, Evanston, IL 60208. E-mail: spruston@northwestern.edu.

Copyright $\odot 2003$ Society for Neuroscience $\quad$ 0270-6474/03/239937-10\$15.00/0 brain dopamine neurons (Blaha et al., 1997; Legault et al., 2000; Floresco et al., 2001). In return, the vSUB receives direct feedback from midbrain dopamine neurons (Gasbarri et al., 1991, 1994a,b, 1996).

The vSUB output is important for regulating dopaminedependent, reward-related behavior and responses to psychostimulants. Simultaneous recordings from NAc and vSUB neurons from freely moving rats indicate that both groups of neurons increase their activity in response to reward anticipation, reward presentation, and spatial location (Martin and Ono, 2000). Disruption of subicular neuronal excitability has several effects. (1) Selective dopamine depletion within the vSUB impairs spatial learning and memory (Gasbarri et al., 1996b); (2) vSUB glutamate receptor (AMPA) blockade attenuates the efficacy of conditioned reward (Hitchcott and Phillips, 1997); and (3) discrete vSUB excitotoxic lesions decrease amphetamine-induced locomotion and cocaine self-administration (Caine et al., 2001). On the other hand, vSUB stimulation increases psychostimulantinduced behaviors (Taepavarapruk et al., 2000). For example, in a model of drug relapse in which rats are trained to selfadminister cocaine before undergoing extinction training, brief theta-burst, but not low frequency $(2 \mathrm{~Hz})$, stimulation of the vSUB triggers reinstatement of cocaine-seeking behavior (Vorel et al., 2001). Enduring changes in the excitability and pattern of vSUB neuronal output could therefore play an important role in modulating the mnemonic and addictive properties of psychostimulants.

To date, prolonged changes in intrinsic neuronal excitability and action potential output resulting from repeated exposure to psychostimulant drugs are known to occur only within the NAc, through downregulation of voltage-gated $\mathrm{Na}^{+}$and $\mathrm{Ca}^{2+}$ chan- 
nels (Zhang et al., 1998, 2002). Given that the NAc receives a major limbic input from the hippocampus, which serves an important role in learning and memory, the purpose of this study was to examine psychostimulant-induced intrinsic neuroadaptations in postsynaptic hippocampal input integration and spike output.

\section{Materials and Methods}

Amphetamine administration and behavior analysis. Rats were screened for their locomotor activity in a locomotor testing apparatus $(34 \times 34$ inch) for 30 min 1 week before receiving five daily subcutaneous injections of saline (SAL) $(1 \mathrm{ml} / \mathrm{kg})$ or amphetamine (AMPH) $(2.5 \mathrm{mg} / \mathrm{kg})$. Two withdrawal times were used to assess the degree of behavioral sensitization: an early withdrawal time (2 d) and a late withdrawal time (14 d). On these days rats were habituated to the test apparatus for $30 \mathrm{~min}$ before an amphetamine challenge injection. All rats received a challenge injection of $2.5 \mathrm{mg} / \mathrm{kg}$ amphetamine on test days, and stereotyped behaviors were scored by trained observers blind to treatment conditions. Stereotyped behaviors were scored similar to procedures established previously (Wolf et al., 1995; Li et al., 1997). Briefly, rats (eight SAL treated and eight AMPH treated) were manually scored sequentially in $25 \mathrm{sec}$ intervals for $2 \mathrm{hr}$ on withdrawal days 2 and 14. Individual rearing bouts and stereotyped continuous rearing and grooming were scored as events if they occurred during the $25 \mathrm{sec}$ observation period for each rat. Continuous rearing was counted if both forelimbs were raised off the surface of the test arena for a period of $25 \mathrm{sec}$. Individual rearing events were also counted each time both forelimbs were raised off the surface. Grooming bouts were scored if they lasted $>10 \mathrm{sec}$.

Slice preparation. For the early (36- to 42 -d-old rats) and late (42- to 50 -d-old rats) withdrawal times, transverse slices with the hippocampus, subiculum, and entorhinal cortex were prepared from mature Wistar rats. Halothane-anesthetized rats were perfused through the heart with chilled artificial CSF (ACSF), and the brain was removed with the head immersed in ice-cold ACSF. The brain was mounted at a $60^{\circ}$ angle to the horizontal plane, and slices $(300 \mu \mathrm{m})$ were cut using a Vibratome (Leica, Nussloch, Germany). Slices were incubated for 20-40 min in a chamber containing warm $\left(34-35^{\circ} \mathrm{C}\right) \mathrm{ACSF}$ and then held at room temperature until they were moved to the recording chamber. For recording, slices were transferred individually to a chamber on a fixed stage of a Zeiss (Oberkochen, Germany) Axioscop equipped with differential interference contrast optics. Recordings were obtained under visual control using a Dage-MTI (Michigan City, IN) tube camera. All experiments were performed during continuous perfusion with ACSF at $32-35^{\circ} \mathrm{C}$.

For synaptic stimulations a stimulating electrode was placed in stratum radiatum in the CA1 region of hippocampus. The current pulse was adjusted in strength to evoke a 3-5 mV EPSP at the soma when the cell was held at $-67 \mathrm{mV}$. To avoid confounds caused by changing stimulus intensity or duration, the synaptic current stimulus, once for each cell at $-67 \mathrm{mV}$, was established and then subsequently unaltered while the cell was tested across a range of holding potentials from -75 to $-50 \mathrm{mV}$ or until the cell spiked. The EPSP amplitude and integral were recorded, and at least six traces were collected at each potential.

Histological procedures. After recording, the slices were placed in paraformaldehyde ( $4 \%$ ) and refrigerated at $4^{\circ} \mathrm{C}$ for $<2$ weeks before processing. We processed the biocytin-filled cells using an avidin-horseradish peroxidase reaction using the Vectastain ABC Kit (Vector Labs, Burlingame, CA). Processed slices were mounted on microscope slides using Mowiol. Neuron reconstructions were performed using a Neurolucida system (MicroBrightField, Inc., Williston, VT) and a Leica microscope with a $63 \times$ oil immersion objective.

Solutions and drugs. Recording ACSF consisted of (in mM): $125 \mathrm{NaCl}$, 25 glucose, $25 \mathrm{NaHCO}_{3}, 2.5 \mathrm{KCl}, 1.25 \mathrm{NaH}_{2} \mathrm{PO}_{4}, 2 \mathrm{CaCl}_{2}$, and $1 \mathrm{MgCl}_{2}$, pH 7.4 (bubbled with $95 \% \mathrm{O}_{2}$ and $5 \% \mathrm{CO}_{2}$ ). For most experiments, synaptic activity was blocked using a mixture of kynurenic acid $(2.5 \mathrm{mM})$, SR $95531(2-4 \mu \mathrm{M})$, and atropine $(1 \mu \mathrm{M})$ added to the ACSF to eliminate glutamate (NMDA and AMPA), GABA , and muscarinic acetylcholinergic synaptic activity, respectively. For experiments involving synaptic stimulation, MK-801 $(20 \mu \mathrm{M})$, SR $95531(2 \mu \mathrm{M})$, and CGP 55845(1 $\mu \mathrm{M})$ were included in the bath to block NMDA, $\mathrm{GABA}_{\mathrm{A}}$, and $\mathrm{GABA}_{\mathrm{B}}$ receptors, respectively. Internal solution compositions are described in current-clamp recordings below. Drugs were purchased from Sigma/RBI (St. Louis, MO).

Current-clamp recordings. Whole-cell, current-clamp recordings were made from the soma using a BVC-700 amplifier (Dagan, Minneapolis, $\mathrm{MN})$. Patch-clamp electrodes were fabricated from thick-walled borosilicate glass and fire polished to resistances of 3-5 M $\Omega$ in the bath. The intracellular solution for whole-cell current-clamp recordings contained (in $\mathrm{mM}$ ): $115 \mathrm{~K}$-gluconate, $20 \mathrm{KCl}, 10 \mathrm{Na}_{2}$-phosphocreatine, $10 \mathrm{HEPES}, 2$ Mg-ATP, and $0.3 \mathrm{Na}-\mathrm{GTP}, \mathrm{pH} 7.3$, and $0.1 \%$ biocytin (for subsequent morphological identification). Data were stored on a Power Macintosh G4 computer (Apple Computers, Cupertino, CA) via an ITC-16 interface (Instrutech, Port Washington, NY). Data acquisition and analysis were performed using custom macros running under Igor Pro (WaveMetrics, Lake Oswego, OR). Voltage was filtered at $5 \mathrm{kHz}$ and digitized at $20 \mathrm{kHz}$.

Data analysis. Data analysis was performed using IGOR Pro 4.0. To calculate the voltage-dependent variation in the membrane potential, we used the average deviation of $7 \mathrm{sec}$ duration traces with no action potentials present. The average power spectra were calculated for $7 \mathrm{sec}$ traces using a Hamming window. Traces were de-trended using a cubic polynomial fit of the raw data that was subtracted from each trace before performing the power spectral density analysis to eliminate lowfrequency $(<0.1 \mathrm{~Hz})$ DC drift in the recording. With use of either a step pulse or simulated (s) EPSC injection, the action potential thresholds were determined by calculating the first derivative $(d V / d t)$ of the action potential and then setting a rate of rise threshold of $30 \mathrm{mV} / \mathrm{msec}$ as the criteria for the action potential inflection point. Integrals were calculated by differentiating the postsynaptic potentials and then performing trapezoidal integration. The start point of the integral calculation was the peak of the voltage deflection, and the calculation stopped at the point that the postsynaptic potential decayed back to baseline.

The sEPSCs were injected into the soma via the recording patch pipette followed $400 \mathrm{msec}$ later by a $5 \mathrm{msec}$ square step pulse scaled to half the sEPSC amplitude to verify accurate bridge balance and capacitance compensation. We set the sEPSCs kinetics with a rise time of $0.2 \mathrm{msec}$ and a decay time of $6 \mathrm{msec}$, yielding sEPSPs that closely resembled actual EPSPs (see Fig. 4). The sEPSPs were increased in amplitude from 100 to $2000 \mathrm{pA}$ until they elicited either a single action potential [regular spiking (RS) cells] or a burst of action potentials [burst spiking (BS) cells]. We used this method to classify vSUB neurons as either BS or RS cells because this is a more physiologically relevant stimulus than a long step pulse. In RS cells we continued to inject larger sEPSCs (100 pA increments) until the cell emitted a burst of action potentials. This was considered to be the "burst threshold" for RS cells.

Statistics for two groups were performed using paired or unpaired Student's two-tailed $t$ tests on normally distributed data and two-tailed $U$ tests for non-normally distributed data. For multiple groups we used ANOVA with or without repeated measures (see Appendix for detailed statistical tests). Post hoc analysis was performed using a Bonferroni corrected $t$ test. All analyses were performed on the raw data with no more than two cells per rat.

\section{Results}

\section{Behavioral sensitization to amphetamine}

We followed an established dosing regimen and scoring procedure for producing long-lasting behavioral sensitization to amphetamine-induced stereotypy (Wolf et al., 1995) (see Materials and Methods). After five daily subcutaneous injections of saline or amphetamine $(2.5 \mathrm{mg} / \mathrm{kg})$, and followed by a withdrawal period (early $=2 \mathrm{~d}$; late $=14 \mathrm{~d}$ ), the rats were scored for their behavioral response to an amphetamine challenge injection. The amphetamine group at the $14 \mathrm{~d}$, late withdrawal time (AMPH/LW) exhibited sensitized stereotyped continuous rearing behavior compared with the saline control group (SAL/LW) $(\mathrm{SAL} / \mathrm{LW}, n=8$, stereotypy score $=0.6 \pm 0.4 ; \mathrm{AMPH} / \mathrm{LW}, n=$ 8 , stereotypy score $=3.5 \pm 1.1 ; p<0.05$ ). A similar trend (albeit nonsignificant) was observed in the amphetamine group at the 


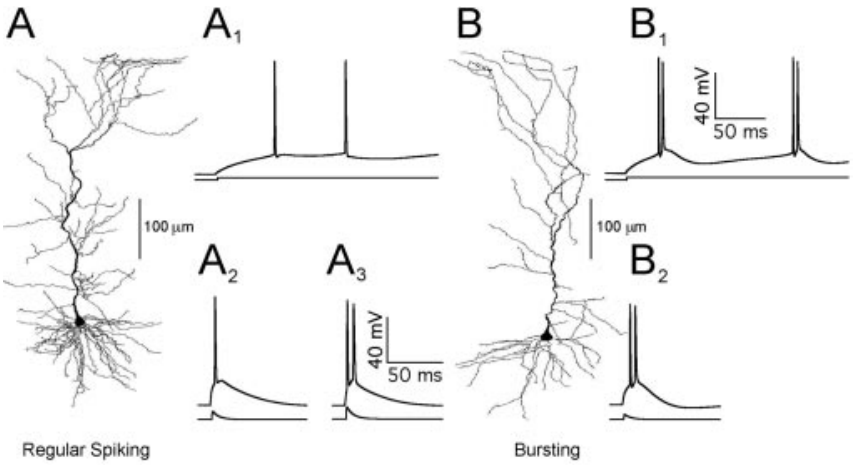

Figure 1. Reconstructions of VSUB neurons and their spike-firing properties. $A, B$, Regular spiking $(A)$ and intrinsically burst-spiking neurons $(B)$ and their respective traces. $A_{1}$ (RS neuron) and $B_{1}$ (BS neuron) show whole-cell current-clamp recordings in response to a long (600 msec) step pulse current injection of $250 \mathrm{pA} . A_{2}$ (RS neuron) and $B_{2}$ (BS neuron) show whole-cell current-clamp recordings in response to brief $\mathrm{EEPSC}(0.2$ rise tau, 6 msec decay tau) of $1500 \mathrm{pA}$ $\left(A_{2}\right)$ or $950 \mathrm{pA}\left(B_{2}\right) . A_{3}$ shows the RS neuron induced to burst by a larger sEPSC $(2000 \mathrm{pA})$. The two cells depicted and their recorded traces were chosen randomly from the $\mathrm{RS}$ and $\mathrm{BS}$ groups. Previous quantitative analyses by our laboratory have shown no morphological differences between the dendritic arborization in RS and BS neurons (Staff et al., 2000).

2-d, early withdrawal time (AMPH/EW) compared with the saline control group (SAL/EW) $(n=8, \mathrm{SAL} / \mathrm{EW}$, stereotypy score $=1.3 \pm 0.4 ; \mathrm{AMPH} / \mathrm{EW}$ stereotypy score $=2.3 \pm 0.6 ; p=$ 0.12 ). Thus, our treatment regimen produced long-lasting behavioral sensitization to amphetamine. Separate groups of rats were used for the subsequent physiology experiments.

\section{Passive and active properties of vSUB regular spiking and bursting neurons after withdrawal from amphetamine}

We recorded from a total of 129 vSUB neurons in this study. On the basis of the action potential response of each cell to a threshold-level sEPSC injection, the cells were classified as RS $(53 \%)$ or BS $(47 \%)$, as seen in Figure 1. The proportion of BS neurons closely matches the proportion of "strong" bursting neurons $(51 \%)$ that we have classified previously on the basis of the ability of subicular neurons to fire repeated bursts in response to a 1 sec current step (Staff et al., 2000). Neurons classified previously as "weak" bursting (on the basis of a single burst response to a 1 sec current step pulse) typically emitted single spikes in response to brief sEPSC injections and were therefore classified as RS neurons in this study. These neurons were able to produce bursts, however, with larger sEPSC injections ( $\sim 30-100 \%$ above their single-spike rheobase) (Fig. $\left.1 A_{2}, A_{3}\right)$. There were no differences in resting potential or the steady-state input resistance $\left(R_{\mathrm{N}}\right)$ measurements between BS and RS cells (Table 1) (see supplemental material, Fig. S1, available at www.jneurosci.org), verifying our previous description of subicular pyramidal neuron physiology (Staff et al., 2000).

In the presence of synaptic blockers, the relative numbers of RS and BS neurons were not different between the SAL and AMPH groups at the early or late withdrawal times, indicating that amphetamine treatment did not change the proportion of RS to BS cells in the vSUB. For spike threshold, amplitude, and rise rate, there were no significant differences between RS and BS neurons, and therefore they were pooled in Figure 2 and normalized to the SAL controls. The neurons from the AMPH/EW group were less excitable to current step or sEPSC injections compared with SAL controls as evidenced by their more depolarized action potential thresholds, smaller action potential amplitudes, and slower rates of action potential rise (Table 1, Fig. 2).
Although no differences were detected in the amount of current necessary to trigger spikes using sEPSC input (sEPSC rheobase) in the SAL and AMPH groups (Table 1) at either withdrawal time point, the sEPSC amplitude necessary to make RS cells burst was significantly larger in the AMPH/EW group compared with the SAL/EW group $(p<0.01)$.

None of the amphetamine-induced changes in Table 1 and Figure 2 that were present at the AMPH/EW time were present at the late withdrawal time. These results indicate that amphetamine treatment and short-term withdrawal decreased the excitability of vSUB neurons by raising their action potential threshold and increasing the current required to induce bursting, without changing input resistance (see supplemental material).

\section{Subthreshold membrane potential oscillations in vSUB neurons}

Subicular pyramidal neurons exhibit near-threshold oscillations that result from subthreshold activation of voltage-gated $\mathrm{Na}^{+}$ channels; the oscillations are blocked by TTX and persist in the presence of ionotropic GABA and glutamate blockers, calcium channel blockers, and $I_{\mathrm{h}}$ channel blockers (Mattia et al., 1997). In the presence of synaptic blockers we measured membrane potential fluctuations while holding the membrane potential at -75 , $-70,-65,-60,-58,-55$, or $-50 \mathrm{mV}$ (7 sec sweeps) or until threshold for the action potential was reached. An analysis of the dependence of the near-threshold membrane potential oscillations on voltage-gated $\mathrm{Na}^{+}$channels was performed on the RS and BS neurons in the saline- and drug-treated groups. Figure 3 shows representative traces of the near-threshold amplification of membrane potential oscillations before and after application of TTX (500 nM), which reduced the voltage-dependent increase in oscillation amplitude. A power spectral density plot showed a dominant peak at $3 \mathrm{~Hz}$ for the nontreated and saline control rats $(n=15)$. TTX decreased the peak without shifting the dominant frequency (Fig. 3B). Comparisons of SAL/EW versus AMPH/EW and SAL/LW versus AMPH/LW indicated that in all groups there was a significant voltage-dependent reduction in the subthreshold oscillations after TTX $(p<0.0001)$. This indicates that most of the near-threshold amplification of membrane potential oscillations in all groups is attributable to voltage-gated $\mathrm{Na}^{+}$ channels.

Amphetamine treatment decreased oscillations at the early but not the late withdrawal time (early, $p<0.0001$; late, NS). There was a significant main effect of holding potential at both withdrawal times (early, $p<0.0001$; late, $p<0.0001$ ), and there was a drug by holding potential interaction at the early but not the late withdrawal time (Early, $p<0.05$; late, NS). These findings indicate that amphetamine treatment and short-term withdrawal reduced, but did not eliminate, $\mathrm{Na}^{+}$channel-mediated subthreshold oscillations.

\section{Voltage-dependent amplification of simulated synaptic input in vSUB neurons}

Synaptic stimulation of the stratum radiatum produced EPSPs from vSUB neurons that exhibited pronounced nonlinear amplification between voltages of -75 and $-55 \mathrm{mV}$ (Fig. 4). As in neocortical neurons (Thomson et al., 1988; Deisz et al., 1991; Stuart and Sakmann, 1995; Gonzalez-Burgos and Barrionuevo, 2001), near-threshold amplification of synaptically generated EPSPs and simulated EPSP (peak and integral) in vSUB RS and $\mathrm{BS}$ neurons was blocked in the presence of TTX (Fig. $4 B-E$ ). This indicates that voltage-gated $\mathrm{Na}^{+}$channels boost near-threshold synaptic inputs in vSUB pyramidal neurons. 
Table 1. In vitro electrophysiological properties of vSUB during withdrawal from amphetamine

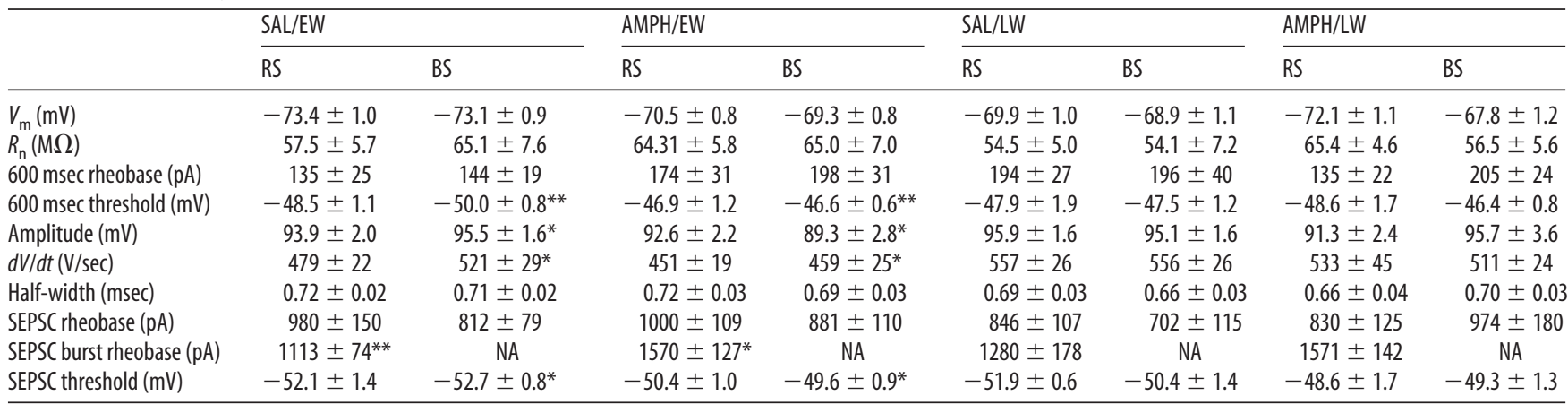

Electrophysiological properties of vSUB neurons at early and late withdrawal times from repeated amphetamine treatment. For both regular spiking (RS) and burst spiking (BS) neurons, measurements of the passive properties of input resistance $\left(R_{N}\right)$ and resting potential $\left(V_{m}\right)$ are presented for the two groups (SAL and AMPH) at an early withdrawal (EW) or late withdrawal (LW) time point. Active properties of the action potentials, such as half-width, threshold, amplitude, and minimum current needed to trigger an action potential (rheobase) were assessed using either a 600 msec current step pulse or an sEPSC input. The minimum sEPSC injection required to initiate a burst in an RS cell (sEPSC rheobase) was performed only in RS cells. ANOVA and two-tailed $t$ test were used to compare treatment groups within each withdrawal time between each neuron classification (RS and BS). All groups were composed of 8 -19 different cells with no more than 2 cells from a single rat. ${ }^{*} p<0.05 ;{ }^{* *} p<0.01$.

A

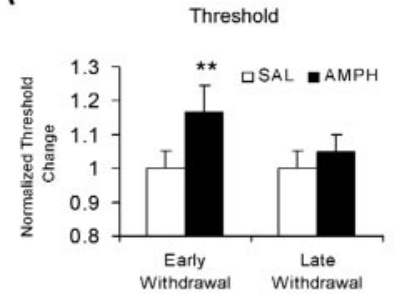

C

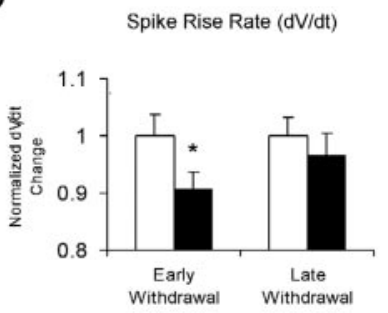

B

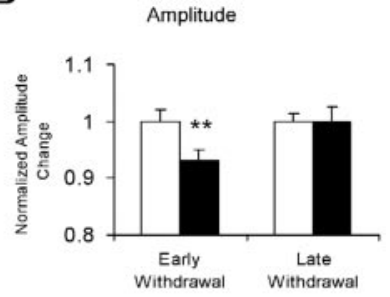

$\mathrm{D}$

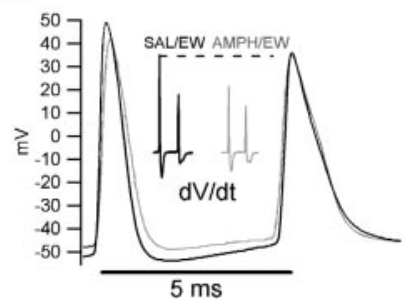

Figure 2. Amphetamine-induced changes in action potential properties. $A-C$ show the significant differences between early withdrawal from repeated SAL or AMPH (gray) on the normalized ( $x$ /average SAL control) change in initial spike threshold (threshold-holding potential) $(A)\left({ }^{* *} p<0.01\right)$ and normalized height $(B)\left({ }^{* *} p<0.01\right)$ and rise rate $(C)\left({ }^{*} p<0.05\right)$. Cells in all treatment groups were held at similar holding potentials before triggering action potentials $(\mathrm{SAL} / \mathrm{EW}=-67.3 \pm 0.3 ; \mathrm{AMPH} / \mathrm{EW}=-67.6 \pm 0.3 ; \mathrm{SAL} / \mathrm{LW}=-67.7 \pm 0.2 ;$ $\mathrm{AMPH} / \mathrm{LW}=-68.0 \pm 0.03$ ). All groups were composed of $16-19$ cells. $D$, Threshold burst in response to a 600 msec step current pulse injection in representative SAL/EW (black) and $\mathrm{AMPH} / \mathrm{EW}$ (gray) BS neurons. The AMPH/EW trace has an elevated initial spike threshold, decreased amplitude, and decreased rise rate ( $d V / d t$, inset), as also seen in $A-C$ and in Table 1 . The inset shows the spike rise rate calculated as the first derivative of the bursts for each group shown in $A$ ( $d V / d t$ : SAL/EW $=605 \mathrm{mV} / \mathrm{msec}$; AMPH/EW $=408 \mathrm{mV} / \mathrm{msec}$ ). There were no differences between the two $B S$ cells on the holding potential before the burst was triggered $(\mathrm{SAL} / \mathrm{EW}=-68.0 \mathrm{mV} ; \mathrm{AMPH} / \mathrm{EW}=-67.5 \mathrm{mV})$.

We examined whether repeated amphetamine treatment and withdrawal could alter near-threshold sEPSP amplification. To study postsynaptic EPSP amplification and avoid possible confounds associated with repeated amphetamine exposure-induced changes in synaptic input or driving force, we used direct simulated EPSC injection that mimicked the kinetics of synaptically evoked responses. As seen in Figure 5, there was a significant reduction in the sEPSP peak amplification in AMPH/EW compared with SAL/EW (peak, $p<0.03$; integral, NS), and there was a significant main effect of the holding potential for both the sEPSP peak and integral (peak, $p<0.0001$; integral, $p<0.0001$ ). There was no drug by holding potential interaction, although a

trend for reduced amplification in the AMPH group was observed (peak, $p=0.06$; integral, NS). A significant decrease in the sEPSP peak in the AMPH/EW versus SAL/EW group at holding potentials of $-65 \mathrm{mV}(p<0.01)$ and $-60 \mathrm{mV}(p<0.05)$ and a significant decrease in the integral at $-60 \mathrm{mV}(p<0.05)$ was detected by a Bonferroni corrected $t$ test. This indicates that short-term amphetamine withdrawal decreases, but does not eliminate, the near-threshold amplification of somatic sEPSPs in vSUB pyramidal neurons.

Unlike the early withdrawal groups, late withdrawal groups showed no significant difference between SAL/LW and AMPH/LW treatments for the peak and integral of the sEPSP. Both groups showed the voltage-dependent enhancement of sEPSPs (peak, $p<0.0001$; integral, $p<0.0001$ ) and no interaction between the groups and the enhancement. This indicates that the initial amphetamine-induced reduction in nearthreshold sEPSP amplification present at the early withdrawal point is no longer present at the late withdrawal time.

To test for the possible effects of residual amphetamine influencing the results that we obtained during the early withdrawal period, we examined whether amphetamine (25-50 $\mu \mathrm{M})$ application to slices changed vSUB passive and active properties, nearthreshold oscillations, sEPSP amplification, and rheobase. There was no effect of acute amphetamine, yet there was a significant effect of holding potential for both groups $\left(F_{(5,66)}=17.7 ; p<\right.$ $0.0001)$ with no drug treatment by holding potential interaction $\left(F_{(5,66)}=1.70\right.$; NS) (see supplemental material, Fig. S2). Therefore, residual amphetamine cannot explain the significant effects that we observed in the AMPH/EW withdrawal group compared with SAL controls. Post hoc analyses showed that no other measures were different between baseline and acute amphetamine exposure, therefore ruling out the possibility that residual amphetamine contributed to the effects that we measured at the early withdrawal point.

To further examine the relationship between spike threshold and sEPSP in RS and BS neurons, we performed a spike-latency analysis in the SAL control groups. To test for spike timing latency, neurons were held at potentials close to threshold (approximately $-60 \mathrm{mV}$ ) and stimulated with sEPSCs just large enough to trigger an action potential (Fig. 6A). There was a significant difference in sEPSP spike latency in the RS (median $=20.1 \mathrm{msec}$ ) and BS (median $=11.8 \mathrm{msec}$ ) neurons (Fig. 6A) (Mann-Whitney $U$ test; $p<0.05)$. In addition, for SAL group RS and BS neurons, there was a significant correlation between spike threshold and spike latency that was reasonably fit by an exponential 
A

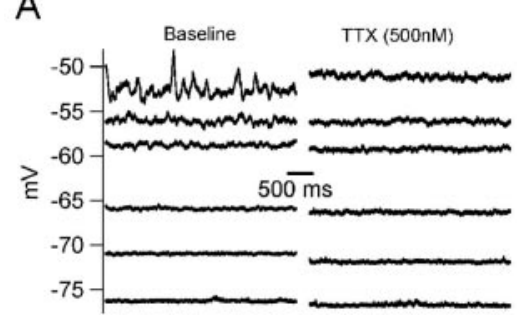

B

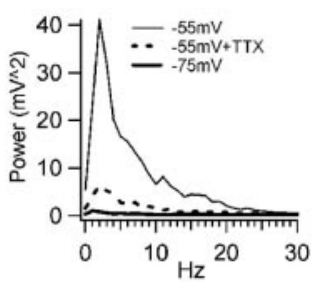

C

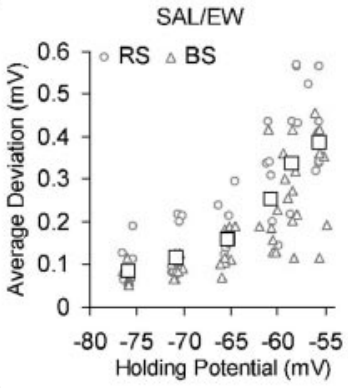

E

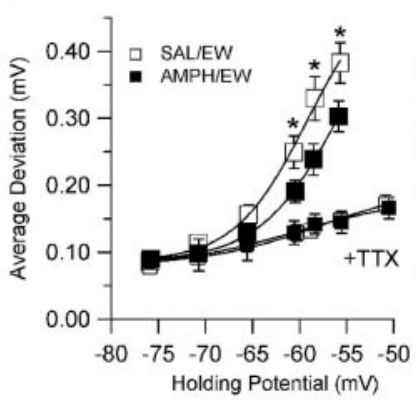

D

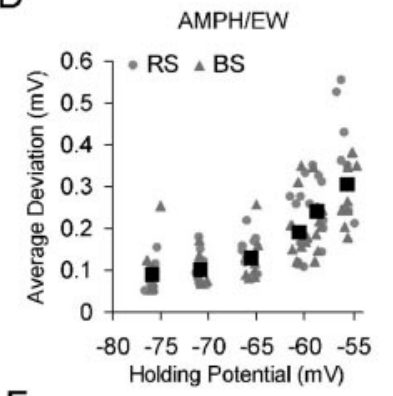

F

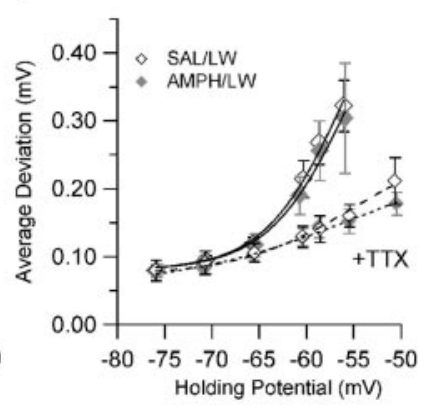

Figure 3. Voltage-dependent amplification of near-threshold membrane potential oscillations in the vSUB RS and BS neurons after withdrawal from repeated saline or amphetamine treatment. $A$ shows the voltage- dependent amplification of subthreshold membrane potential oscillations measured as average deviation before (Baseline) and after TTX (500 nм). B, The power spectral density plot of the subthreshold membrane potential oscillations from pooled RS and BS vSUB neurons $(n=15)$ in nontreated and SAL controls, showing a voltage-dependent peak at $3 \mathrm{~Hz}$ at $-55 \mathrm{mV}$ and its attenuation after TTX ( $500 \mathrm{~nm}$ ). (and $D$ show a scatter plot of the average deviation of the $R S$ and $B S$ membrane potential oscillations at several holding potentials $(-75$ to $-55 \mathrm{mV})$ in the SAL/EW ( $C$ and AMPH/EW (D) early withdrawal groups. Open (SAL) and filled (AMPH) squares represent the pooled RS and BS values for each treatment group. Eshows that both treatment groups show a significant voltage-dependent amplification of the membrane potential oscillations (SAL/EW, $n=15, p<0.001$; AMPH/EW, $n=19, p<$ 0.001 ; see Appendix). Scatter plots for the late withdrawal are not shown because there were no differences between treatment groups, and the scatter between $\mathrm{RS}$ and $\mathrm{BS}$ neurons was similar to the early withdrawal time $(C, D)$. E and $F$ show the pooled average of $\mathrm{RS}$ and $B S$ neurons for each treatment group. Compared with SAL/EW, the AMPH/EW group had significantly decreased voltage-dependent amplification of the membrane potential oscillations in the nearthreshold voltage range between -60 and $-55 \mathrm{mV}(E)\left({ }^{*} p<0.05\right)$. TTX ( $\left.500 \mathrm{~nm}\right)$ greatly reduced voltage-dependent oscillation amplification and eliminated the drug-treatment differences. $F$, Late withdrawal voltage-dependent amplification of the membrane potential oscillation amplitude in the SAL/LW $(n=17)$ and AMPH/LW $(n=15)$ groups before and after attenuation by TTX. Symbols represent the mean average deviation and holding potential; error bars represent \pm SEM average deviation. Peak-to-peak oscillations were 2-10 times larger than the average deviation for each trace.

regression equation (RS, $R^{2}=0.30, p<0.01$; BS, $R^{2}=0.20, p<$ $0.05)$. This significant relationship between spike threshold and latency (Fig. $6 \mathrm{~B}$ ) could not be attributed to differences in holding potential because there was no significant correlation between holding potential and spike latency (Fig. 6C).

We next examined whether withdrawal from repeated amphetamine exposure could induce changes in the sEPSP spike

A

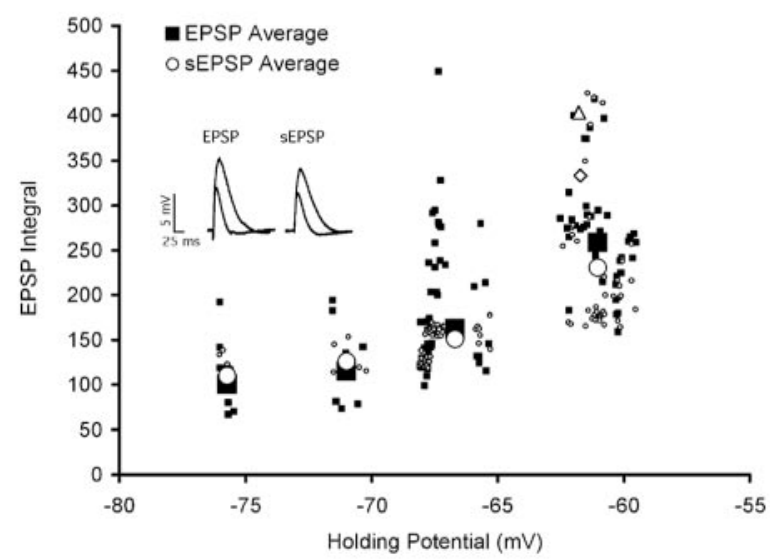

B

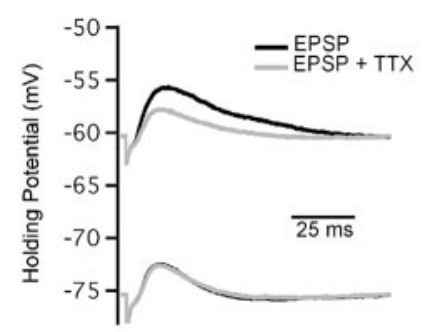

C
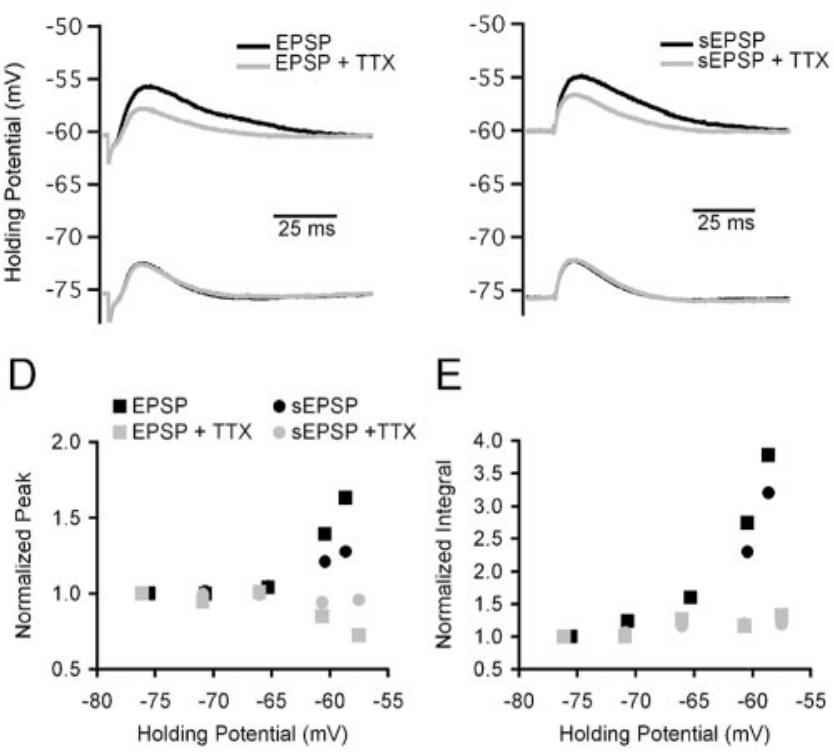

E

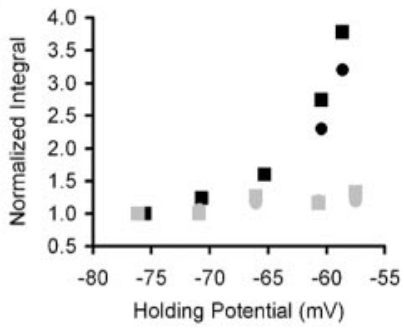

Figure 4. Voltage-dependent amplification of synaptically generated and simulated EPSPS in VSUB pyramidal neurons is dependent on TTX-sensitive $\mathrm{Na}^{+}$channels. A, Scatter plot shows the similarity in voltage-dependent amplification between synaptically generated EPSPs and simulated EPSPs from negative holding potentials $(-75 \mathrm{mV})$ to near-threshold potentials $(-59 \mathrm{mV})$. EPSPs (filled squares) and sEPSPs (open circles) were collected in the same sweep 500 msec apart. The averages for EPSPs (large filled squares) and the sEPSPs (large open circles) were taken from six consecutive sweeps in both RS and BS neurons $(n=4)$. The inset shows superimposed representative sweeps of EPSPs (open triangle) and sEPSPs (open diamond) at both negative and near-threshold holding potentials. $B$ and C show near-threshold EPSP and sEPSP amplification before and after bath application of a submaximal concentration of TTX (50 $\mathrm{nm}$, gray traces). $D$ and $E$ show the average $(n=2)$ voltage-dependent TTX-sensitive amplification of the peak $(D)$ and integral ( $E$ ) from EPSPs (squares) and SEPSPs (TTX, $50 \mathrm{~nm}$, circles). NMDA, GABA $A_{A}$ and GABA ${ }_{B}$ receptors were blocked by using MK-801 (20 $\left.\mu \mathrm{M}\right)$, SR $95531(2 \mu \mathrm{M})$, and CGP $55845(1 \mu \mathrm{M})$ in the bath solution.

timing latencies. There was no significant main effect for RS neurons $\left(F_{(2,40)}=1.16\right.$; NS); however, there was a significant difference between the latencies for BS neurons in the SAL (pooled EW and LW), AMPH/EW, and AMPH/LW groups $\left(F_{(2,42)}=7.29\right.$; $p<0.002)$. BS neurons in the AMPH/EW group had significantly delayed initial spikes compared with the SAL controls $(p<0.01)$ (Fig. 7B). For the early withdrawal time, differences between groups were not caused by differences in holding potential (Fig. 7, legend). There were no differences in the spike latencies between 
A

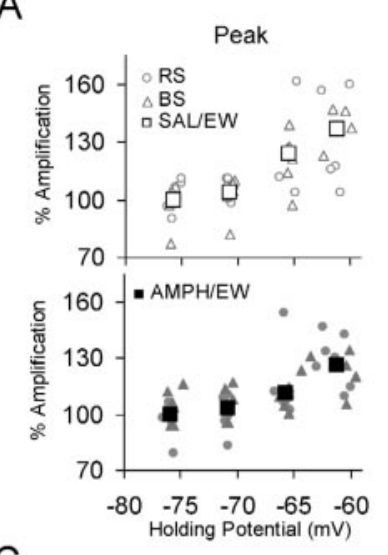

C

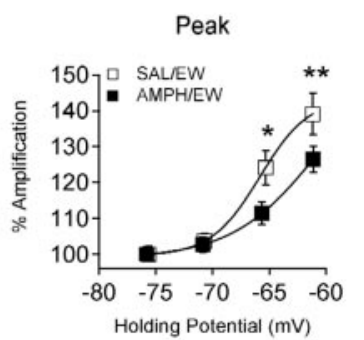

D

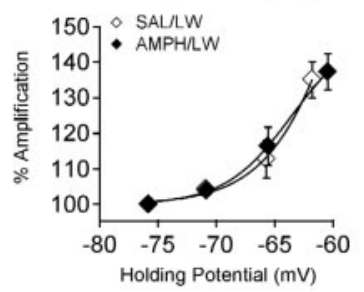

B

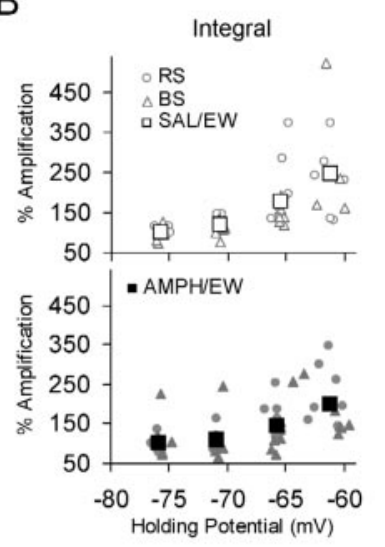

Integral
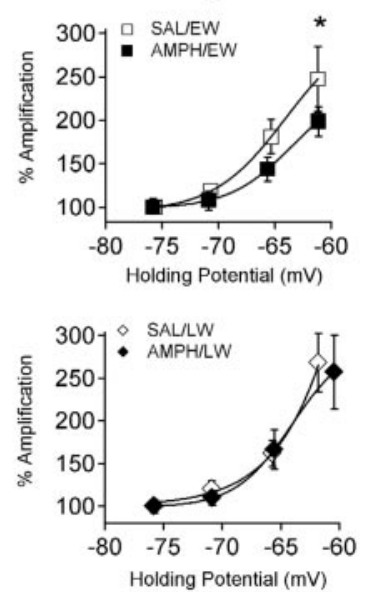

Figure 5. Voltage-dependent amplification of sEPSP input in vSUB pyramidal neurons after early or late withdrawal from repeated saline or amphetamine treatment. $A$ and $B$ show scatter plots of the near-threshold peak and integral amplification in RS and BS neurons from the SAL/EW control (top panels) and AMPH/EW groups (bottom panels) groups. Both groups exhibited significant voltage-dependent amplification of the sEPSPs $(p<0.001)$. No differences in the amplification distribution between RS and BS neurons in either drug group at either withdrawal time were detected; therefore they were pooled for the drug comparisons (SAL/EW, $\square ; \mathrm{AMPH} / \mathrm{EW}, \mathbf{\square}$ ). ( shows an amphetamine-induced reduction in the peak and integral of near-threshold amplification of the sEPSP in the AMPH/EW group (SAL, $n=12 ; \mathrm{AMPH}, n=12$; ${ }^{* *} p<0.01 ;{ }^{*} p<0.05$; see Appendix). Scatter plots for the late withdrawal time are not shown because there were no treatment group differences, and the scatter for $\mathrm{RS}$ and $\mathrm{BS}$ neurons was similar to those shown for the early withdrawal $(A, B)$. $D$ shows the return to normal nearthreshold peak (left) and integral (right) amplification of the sEPSP in SAL/LW and AMPH/LW groups. All groups consisted of $6-12$ cells.

the saline and drug groups at the late withdrawal time. These results indicate that repeated amphetamine exposure and withdrawal increase the near-threshold sEPSP spike latency selectively in BS neurons and may be caused by the elevated spike threshold in the AMPH group (Table 1).

Together our results suggest that in the early stages of withdrawal from amphetamine there is a decrease in the voltage-gated $\mathrm{Na}^{+}$conductance. We therefore reasoned that we should be able to mimic the effects of amphetamine-induced plasticity by slightly reducing $\mathrm{Na}^{+}$channel availability using TTX. Rather than arbitrarily picking a fixed steady-state "low" concentration of TTX to test all cells, we chose to continuously $(0.1 \mathrm{~Hz})$ monitor near-threshold sEPSP amplification and bursting threshold and spike latency as TTX (500 nM) slowly washed into the recording chamber. This allowed us to detect the gradual effects of $\mathrm{Na}+$ channel downregulation until all action potentials were com-

A

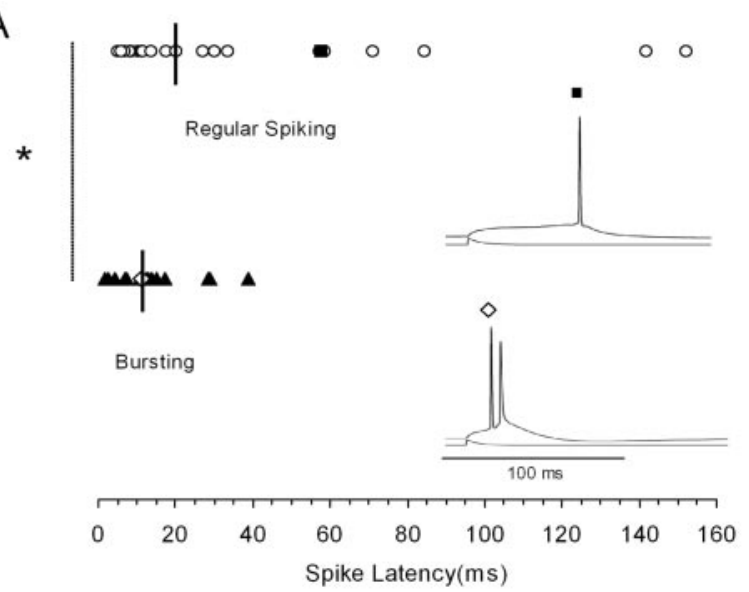

B
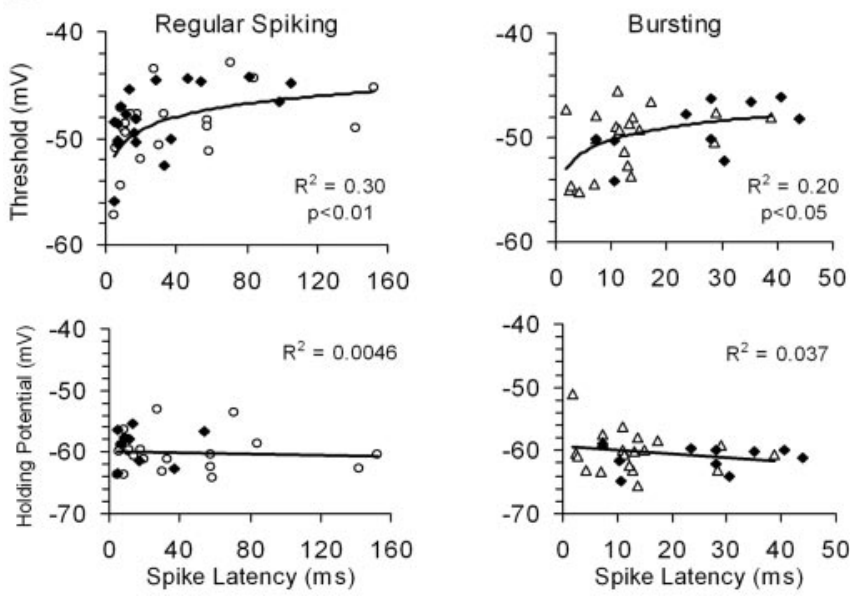

Figure 6. Near-threshold spike timing variability in RS and BS vSUB neurons. A shows a scatter plot and median line of the action potential timing response to near-threshold sEPSC injection in RS (open circles, $n=19$ ) and BS (filled triangles, $n=16$ ) neurons. The nearthreshold spike timing median latencies were significantly different between RS and BS neurons ( ${ }^{*} p<0.05$; Mann-Whitney $U$ test). RS and BS neurons were held at similar holding potentials ( $R S=-60.07 \pm 0.73 \mathrm{mV} ; \mathrm{BS}=-60.08 \pm 0.70)$, and there were no differences in the amplitude of the sEPSC current injection between groups (see supplemental material, Fig. S1). The insets show representative RS (top) and BS (bottom) traces, symbolized in the scatter plot by a filled square (RS) and an open diamond (BS). $B$ shows the action potential threshold (top panels) and holding potential (bottom panels) relationship to the spike latency triggered by a near-threshold input. To optimize the $R^{2}$ values, the action potential threshold/latency data were fit by a logarithmic equation (see Appendix) to the pooled SAL/EW and SAL/LW control groups ( $\left.\mathrm{RS}, R^{2}=0.30, p<0.01 ; \mathrm{BS}, R^{2}=0.20, p<0.05\right)$, and the holding potential/ latency data were fit with a linear equation ( $\left.R S, R^{2}=0.0046 ; \mathrm{BS}, R^{2}=0.037\right)$. The AMPH/EW group (filled diamonds) exhibited the same relationship between threshold and spike latency as the SAL control group (AMPH RS, $n=16$; AMPH BS, $n=10$ ).

pletely inhibited at steady-state concentrations of TTX (500 nM). The results are seen in Figure 8, which shows that a minimal reduction in $\mathrm{Na}^{+}$conductance increases the spike threshold and delays the spike latency. A significant positive linear relationship between spike threshold and spike latency was observed for four neurons in the presence of low TTX $\left(p<0.01 ; R^{2}=0.99\right)$. Minimal $\mathrm{Na}^{+}$channel downregulation also increased the action potential threshold $(n=4$; before TTX $=-49.5 \pm 0.52 \mathrm{mV}$; after TTX $=-48.6 \pm 0.58 \mathrm{mV} ; p<0.05)$ and decreased the nearthreshold oscillations average deviation $(n=4$; before TTX $=$ $0.13 \pm 0.027 \mathrm{mV}$; after TTX $=0.11 \pm 0.022 \mathrm{mV} ; p<0.02)$, and sEPSP amplification $(n=4$; before TTX $=6.63 \pm 0.63 \mathrm{mV}$; after $\mathrm{TTX}=6.28 \pm 0.70 \mathrm{mV} ; p<0.05)$ at the same time that it delayed 
A

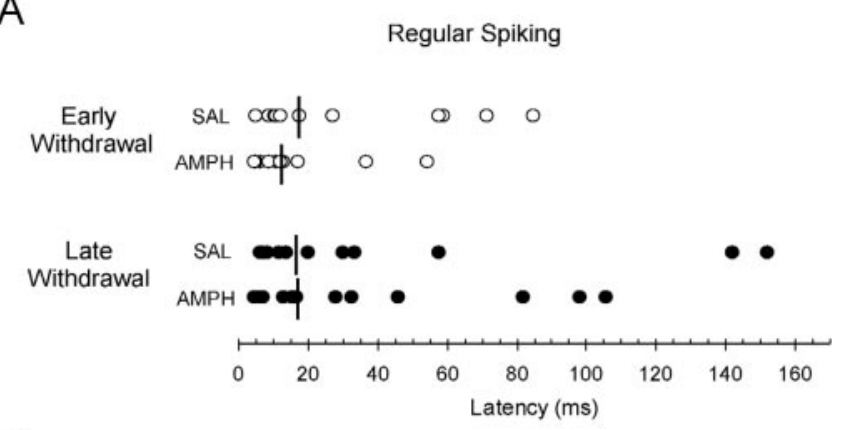

B
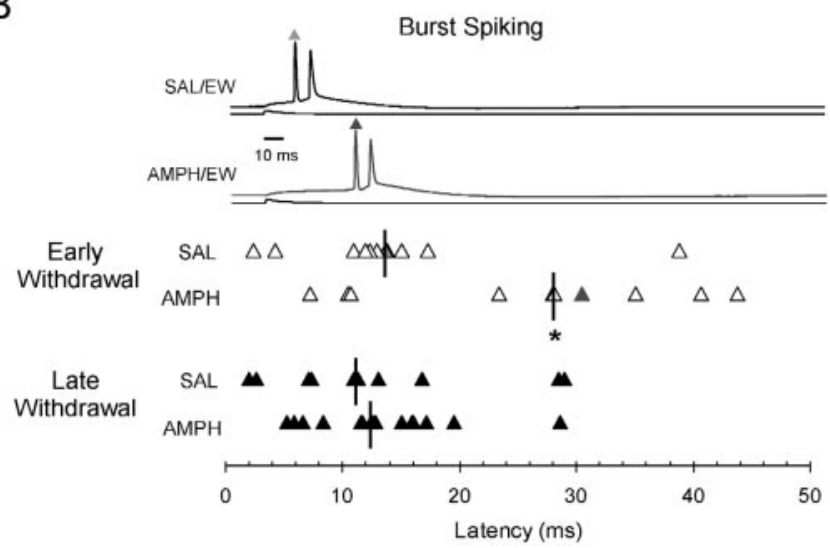

Figure 7. Near-threshold spike timing variability after early or late withdrawal from saline or amphetamine in RS and BS vSUB neurons. $A$ and $B$ show scatter plots of the action potential timing response of $R S$ and $B S$ neurons to near-threshold $S E P S C$ injection at the early or late withdrawal times from SAL or AMPH (RS: SAL, $n=10 ; \mathrm{AMPH}, n=8$, open circles; BS: SAL, $n=$ 8; AMPH, filled triangles, $n=9$ ). At the early withdrawal, the near-threshold spike timing latencies in BS neurons were significantly different compared with SAL withdrawn neurons $\left({ }^{*} p<0.05\right.$; Mann-Whitney $U$ test). All groups were held at similar holding potentials (SAL/EW $\mathrm{RS}=59.5 \pm 0.74 \mathrm{mV} ; \mathrm{SAL} / \mathrm{EW} \mathrm{BS}=61.3 \pm 0.81 \mathrm{mV} ; \mathrm{AMPH} / \mathrm{EW} \mathrm{RS}=58.9 \pm 0.96 \mathrm{mV}$; $\mathrm{AMPH} / \mathrm{EW} \mathrm{BS}=61.2 \pm 0.62 \mathrm{mV} ; \mathrm{SAL} / \mathrm{LW} \mathrm{RS}=-60.6 \pm 0.57 \mathrm{mV} ; \mathrm{SAL} / \mathrm{LW} \mathrm{BS}=-59.2 \pm$ $0.94 \mathrm{mV} ; \mathrm{AMPH} / \mathrm{LW} \mathrm{RS}=-59.12 \pm 0.75 \mathrm{mV} ; \mathrm{AMPH} / \mathrm{LW} \mathrm{BS}=59.4 \pm 1.00 \mathrm{mV}$ ), and there were no differences in the amplitude of the SEPSC current injection between groups (see supplemental material, S1). B inset shows representative SAL/EW BS (top) and AMPH/EW BS (bottom, gray) traces, symbolized in the respective scatter plots by filled gray triangles. As above, all groups were held at similar holding potentials.

the spike latency $(n=4$; before TTX $=11.8 \pm 2.8 \mathrm{msec}$; after TTX $=21.7 \pm 5.9$ msec; $p<0.05$ ) (Fig. 8). These results closely match the effects observed during short-term withdrawal from amphetamine, suggesting that repeated amphetamine treatment and withdrawal decrease $\mathrm{Na}^{+}$channel function in vSUB neurons.

\section{Discussion}

\section{Effects of amphetamine withdrawal on action potential firing} in vSUB neurons

Short-term withdrawal from amphetamine raised the action potential threshold, lowered the action potential height, decreased the rate of action potential rise, and decreased the likelihood and timing of bursting in vSUB neurons compared with SAL controls (Table 1, Fig. 2). Similar results on spike threshold and amplitude have been reported in NAc medium spiny neurons during shortterm withdrawal (1-3 d) from repeated cocaine treatment (Zhang et al., 1998). In fact, short-term withdrawal from cocaine decreases whole-cell $\mathrm{Na}^{+}$and high voltage-activated $\mathrm{Ca}^{2+}$ current (N-type and R-type), which makes the NAc neurons less excitable (Zhang et al., 1998, 2002). There were no changes in the proportion of RS and BS neurons after amphetamine treatment
A

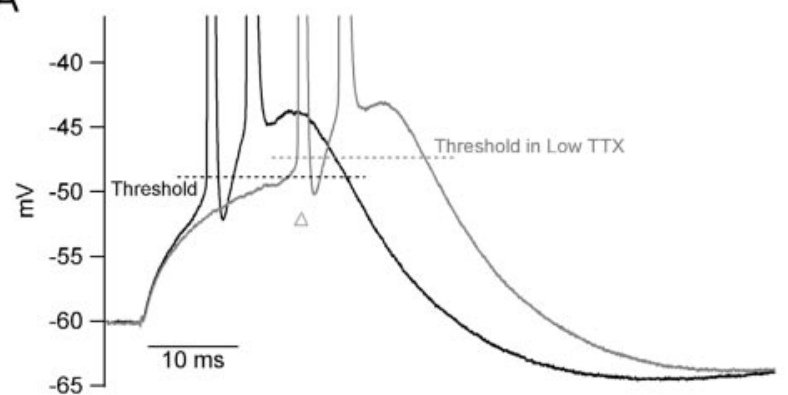

B
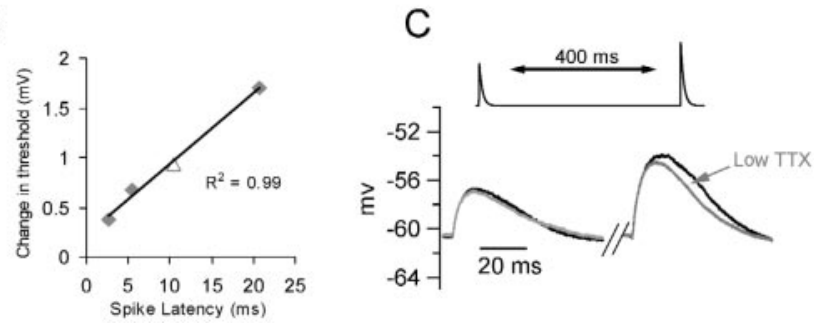

Figure 8. TTX-induced downregulation of voltage-gated $\mathrm{Na}^{+}$channels mimics the effects of early withdrawal from amphetamine. $A$ shows a representative burst response to an SEPSC ( $400 \mathrm{pA})$ somatic input before (black trace) and during (gray trace, open triangle) infusion of TTX on BS action potential threshold and spike timing latency. The gray open triangle shows the TTX trace in the scatter plot in $B$. $B$ shows the relationship between the spike threshold and latency during infusion of low concentrations of TTX. A linear fit line shows a positive correlation between threshold and spike latency $\left(R^{2}=0.99\right)$. The holding potentials were similar before $(-60.3 \pm 0.38 \mathrm{mV})$ and after TTX $(-60.6 \pm 0.45 \mathrm{mV})$. ( shows the subthreshold sEPSP response to a $200 \mathrm{pA}$ (left) and $300 \mathrm{pA}$ (right) sEPSC somatic input taken 400 msec apart and 300 msec before the burst trace seen in $A$. Note the near-threshold amplification only in the $300 \mathrm{pA}$ trace. The subthreshold sEPSCs were injected every $300-400 \mathrm{msec}$ while TTX washed in the recording chamber. The before and after TTX traces shown were 40 sec apart. Under our experimental conditions, TTX ( $500 \mathrm{~nm}$ ) reached sufficient concentrations in the recording chamber to eliminate the action potentials between 240 and $300 \mathrm{sec}$. All TTX time points were taken between 30 and 60 sec from the entry of TTX into the recording chamber. Action potentials in $A$ are truncated.

and withdrawal, suggesting that the action potential-dependent $\mathrm{Ca}^{2+}$ tail current, which correlates with the strength of bursting (Jung et al., 2001), was not altered. It is possible that decreased action potential output resulting from psychostimulant-induced plasticity (PSIP) of voltage-gated $\mathrm{Na}^{+}$channels is a common mechanism affecting dopamine target structures such as NAc and vSUB (and perhaps others).

\section{Near-threshold membrane potential amplification and spike timing in vSUB neurons}

Experimental and computational studies in the entorhinal cortex indicate that near-threshold oscillations arise from the stochastic flicker of voltage-gated $\mathrm{Na}^{+}$channels, which may serve to amplify responses to weak synaptic signals near the spike threshold (White et al., 1998). Consistent with this hypothesis, our results indicate that near-threshold membrane potential oscillations and EPSP amplifications were eliminated by TTX. The reduction of these oscillations during short-term withdrawal from amphetamine (20\% reduction at $-55 \mathrm{mV}$ compared with SAL) (Figs. 3E, $5 C$ ) is therefore consistent with an amphetamine-induced downregulation of $\mathrm{Na}^{+}$channel function.

The near-threshold sEPSP-evoked spike latency distributions in RS and BS neurons were different. BS neurons had a narrow window $(8-20 \mathrm{msec})$, whereas RS neurons had a larger window $(10-60 \mathrm{msec})$. The relationship between the spike threshold and the spike latency was such that more depolarized thresholds were 
associated with longer latencies. Short-term withdrawal from amphetamine increased the spike threshold by $\sim 3 \mathrm{mV}$ and doubled the sEPSP-evoked spike timing latency in bursting neurons.

\section{Mechanisms of psychostimulant-induced plasticity of intrinsic neuronal excitability}

Amphetamine produces a prolonged increase in dopamine neurotransmission by reversing the dopamine reuptake transporter on the dopamine terminals (Jones et al., 1998). It is unknown whether amphetamine-induced plasticity in the vSUB is caused by elevated postsynaptic dopamine signaling or dopaminemediated synaptic changes in network inputs to the vSUB, or both; however, the expression of PSIP of vSUB intrinsic neuronal excitability at the early withdrawal is clearly postsynaptic. It appears likely that, like PSIP in the NAc, vSUB PSIP decreases the function of $\mathrm{Na}^{+}$channels, because we were able to reproduce the effects of short-term withdrawal from amphetamine using low concentrations of TTX. This procedure reduced $\mathrm{Na}^{+}$channel availability enough to decrease near-threshold oscillations and sEPSP boosting and increase the spike threshold and EPSPevoked spike-timing latency, without inhibiting action potential bursting (Figs. 3, 8).

PSIP of voltage-gated $\mathrm{Na}^{+}$channels in the NAc neurons is thought to arise from repeated dopamine D1 receptor-mediated activation of the protein kinase A (PKA) pathway, which increases phosphorylation of $\mathrm{Na}^{+}$channels, thereby decreasing their function (Zhang et al., 1998). D1/PKA-mediated phosphorylation of $\mathrm{Na}^{+}$channel function has been shown to be voltage dependent, exhibiting a greater inhibition at membrane potentials near spike threshold (approximately $-50 \mathrm{mV}$ ) (Cantrell et al., 1999). Interestingly, all of the short-term effects of repeated amphetamine exposure in this study were observed at or above near-threshold potentials ( -60 to $-50 \mathrm{mV}$ ), which is where PKA activation has recently been shown to exhibit a greater ability to inhibit $\mathrm{Na}^{+}$channel function by increasing the proportion of $\mathrm{Na}^{+}$channels in the slow-inactivated state (Carr et al., 2003). Although speculative, it is possible that repeated amphetamine exposure enhances the PKA pathway and increases the proportion of voltage-gated $\mathrm{Na}^{+}$channels in the slow-inactivated state.

\section{Functional consequences of PSIP for synaptic integration and plasticity in vSUB}

Computer modeling studies have suggested that bursting codes for sudden increases in synaptic input (Kepecs et al., 2002), which may be theoretically important in the dopamine system for signaling salient environmental stimuli (for review, see Cooper, 2002). Burst-mode spiking may transmit important information by increasing the reliability of synaptic transmission (Miles and Wong, 1986; Lisman, 1997; Snider et al., 1998). Under normal conditions, in vSUB target structures such as the NAc, stimulation of subicular glutamatergic projection neurons increases their excitability (Finch, 1996), which would likely be enhanced by bursting. For example, excitatory outputs from the ventral hippocampus set the timing and amplitude of the prolonged ( 200-500 msec) subthreshold "up" states in medium spiny neurons of the NAc. These up states are required for NAc medium spiny neurons to spike, thus making limbic projections capable of "gating" input into the NAc neurons (O'Donnell and Grace, 1995). Combined with the established PSIP in the NAc (Zhang et al., 1998, 2002), PSIP in the vSUB may result in diminished and inappropriately timed excitatory drive to the NAc that could produce a coordinated decrease in excitability leading to disruptions in dopamine-mediated behaviors.
Postsynaptic modulation of the near-threshold spike latencies may influence not only ongoing neural processing but also synaptic plasticity [e.g., long-term depression (LTD) or long-term potentiation (LTP)], which is dependent on the EPSP-spike timing relationship [spike timing-dependent plasticity (STDP)]. The strength and precise (millisecond) timing of presynaptic input and postsynaptic spiking have a strong influence on the polarity and degree of STDP (Markram et al., 1997; Bi and Poo, 1998; Nishiyama et al., 2000; Sjostrom et al., 2001). Our results in vSUB may be significant for STDP because we observed significant differences in the EPSP-spike timing latencies between the RS (latency $=20 \mathrm{msec}$ ) and BS (latency $=12 \mathrm{msec}$ ) neurons (Fig. 7). In addition, short-term withdrawal from amphetamine doubled the EPSP-spike timing latency in BS neurons (SAL = $14 \mathrm{msec}$; AMPH $=28 \mathrm{msec}$ ), a difference that would be predicted to change the polarity of STDP at synapses onto vSUB neurons or from vSUB to its targets.

Not only is precise timing important for synaptic plasticity, but so is the amplitude of the postsynaptic response. Weak synaptic EPSPs fail to produce LTP when paired with appropriate EPSP-spike timing, but a postsynaptic (somatic) current injection that boosts the EPSP a few millivolts rescues LTP (Sjostrom et al., 2001). Near-threshold $\mathrm{Na}^{+}$currents could provide the necessary postsynaptic EPSP boosting to bring weak EPSPs into an appropriate timing and depolarization window to permit LTP. Our finding that repeated amphetamine treatment reduced nearthreshold amplification of the sEPSP peak (10\% reduction) and integral (20\% reduction) in vSUB neurons suggests that under these conditions vSUB synaptic output may be diminished, leading to impaired vSUB-dependent associative learning.

\section{Behavioral consequences of PSIP in vSUB neurons}

Repeated exposures to psychostimulant drugs are capable of inducing psychosis in humans and long-lasting behavioral sensitization associated with impaired dopamine transmission, addiction, and schizophrenia (Robinson and Becker, 1986; Paulson et al., 1991; Strakowski et al., 1996; Lieberman et al., 1997; Wolf, 1998; Laruelle, 2000; Ujike, 2002; Castner and Goldman-Rakic, 2003;). Our results are consistent with others showing that repeated exposure to amphetamine produces long-lasting behavioral sensitization (Paulson et al., 1991; Wolf et al., 1995; Li et al., 1997). The fact that reduced intrinsic excitability in vSUB physiology was limited to the early withdrawal time point indicates that PSIP in the vSUB may be related to the induction of sensitization or expression of locomotor depression but is not necessary for the long-term expression of sensitization.

Short-term withdrawal from amphetamine produces disruptions in conditioned associative learning (Murphy et al., 2001; Russig et al., 2002). Selective lesions of the ventral hippocampus and vSUB disrupt dopamine transmission, sensorimotor gating, conditioned learning, and behavioral response to psychostimulant drugs (Caine et al., 2001). The impairments in sensory gating and associative learning are reversed by dopamine antagonists and exacerbated by amphetamine (Caine et al., 2001; Russig et al., 2003). Thus it appears that precise regulation of dopamine tone and vSUB excitability is critical for proper sensorimotor gating and associative learning.

In addition to these effects, enhancement of dopamine neurotransmission by administration of amphetamine directly into the NAc increases the reinforcing effects of vSUB selfstimulation, suggesting that a cooperative relationship between enhanced dopamine tone in the NAc and the subiculum influences motivated behavior (Sweet and Neill, 1999). PSIP of vSUB 
neuronal excitability may lead to altered synaptic integration and EPSP-spike timing relationships in these circuits, which in turn may participate in the impaired sensorimotor gating and associative learning deficits that are associated with psychomotor stimulant withdrawal and other mesolimbic dopamine system disorders.

\section{Appendix}

Here we report the ANOVA statistics associated with the nearthreshold membrane potential oscillations and sEPSP amplification presented in Figures 3 and 6 . The curve-fitting equations for Figures 3, 5, and 6 are also presented.

For Figure 3, separate two-way (before and after TTX) repeated measure (holding potential) ANOVA comparisons of SAL/EW versus AMPH/EW and SAL/LW versus AMPH/LW were performed. The ANOVA indicated that TTX reduced oscillations in all groups (SAL/EW: $F_{(1,89)}=152.26, p<0.0001$; SAL/ LW: $F_{(1,101)}=64.9, p<0.0001 ; \mathrm{AMPH} / \mathrm{EW}: F_{(1,113)}=116.77$, $p<0.0001$; AMPH/LW: $\left.F_{(1,83)}=43.7, p<0.0001\right)$. All groups showed a significant holding potential repeated measure effect $\left(\mathrm{SAL} / \mathrm{EW}: F_{(5,84)}=26.37, p<0.0001 ; \mathrm{SAL} / \mathrm{LW}: F_{(5,96)}=18.6\right.$, $p<0.0001$; AMPH/EW: $F_{(5,108)}=26.13, p<0.0001 ;$ AMPH/ LW: $\left.F_{(5,78)}=14.4, p<0.0001\right)$ and a significant interaction between the TTX condition and holding potential (SAL/EW: $F_{(5,84)}=20.8, p<0.0001$; SAL/LW: $F_{(5,96)}=12.6, p<0.0001: ;$ $\mathrm{AMPH} / \mathrm{EW}: F_{(5,113)}=19.54, p<0.0001 ; \mathrm{AMPH} / \mathrm{LW}: F_{(5,78)}=$ 9.96, $p<0.0001$ ). Two-way (SAL/EW vs AMPH/EW and SAL/LW vs AMPH/LW) ANOVA showed that amphetamine treatment decreased oscillations at the early but not the late withdrawal time (early: $F_{(1,113)}=18.0, p<0.0001$; late: $F_{(5,101)}=0.39$; NS). There was a significant main effect of holding potential at both withdrawal times (early: $F_{(5,108)}=18.0, p<0.0001$; late: $\left.F_{(5,102)}=46.4, p<0.0001\right)$, and there was a drug group by repeated measure (holding potential) interaction only at the early but not late withdrawal time (early: $F_{(5,108)}=2.31, p<0.048$; late: $F_{(5,102)}=0.32$; NS). The formula for average deviation was $(\Sigma \mid$ deviations $\mid) / n$.

For Figure 3, we used a sigmoidal curve fit equation base + $\max /\left[1+\exp \left(1 / 2_{\max }-x\right) /\right.$ rate $\left.\left.)\right]\right\}$ to fit the lines for the voltagedependent amplification of the near-threshold membrane potential oscillations for pooled BS and RS neurons (Figs. $3 E, F$ ) (base $=0.08,0.08 ; \max =0.42,0.46 ; 1 / 2 \max =-59.1,-55.4$; rate $=3.9,4.3$; for TTX: base $=0.08,0.08 ; \max =0.12,0.10$; $1 / 2_{\max }=-57.8,-60.4 ;$ rate $=6.15,6.23$ for SAL/EW and AMPH/ EW, respectively). For the late withdrawal times, base $=0.08$, $0.08 ; \max =0.63,0.50 ; 1 /{ }^{2} \max =-54.53,-55.1$; rate $=4.3,4.3$; for TTX: base $=0.07,0.06 ; \max =0.2,0.2 ; 1 / 2 \max 55.0,-55.0$; rate $=6.1,9.2$ for SAL/LW, AMPH/LW, respectively.

For Figure 5, there was a significant reduction in the sEPSP peak amplification in AMPH/EW compared with SAL/EW (peak: $F_{(1,27)}=5.32 ; p<0.03$; integral: $\left.F_{(1,27)}=2.28 ; p=0.14\right)$; there was a significant main effect of the holding potential for both the sEPSP peak and integral (peak: $F_{(3,81)}=47.01 ; p<0.0001$; integral: $\left.F_{(3,81)}=35.95 ; p<0.0001\right)$. There was a marginally significant drug group by holding potential interaction (peak: $F_{(3,81)}=$ $2.48 ; p=0.06$ ). The late withdrawal groups showed no significant main drug treatment effect for the peak and integral of the sEPSP (peak: $F_{(1,23)}=0.20$; NS; integral: $F_{(1,23)}=0.03$; NS). There was a significant main effect of holding potential (peak: $F_{(3,72)}=55.5$; $p<0.0001$; integral: $\left.F_{(3,66)}=44.4 ; p<0.0001\right)$ and no interaction between the holding potential and drug treatment (peak: $F_{(3,66)}=0.19 ; p=$ NS; integral: $\left.F_{(3,66)}=0.12 ; p=\mathrm{NS}\right)$. The voltage-dependent amplification of the sEPSP in all groups was fit by a sigmoid as described above (Fig. 3) (for peak: base $=99.5$, 98.8, 98.9, 98.6; $\max =44.1,48.1,58.8,61.4 ; 1 / 2_{\max }=-65.8$, $-64.1,-60.6,-62.3$; rate $=2.1,3.2,3.8,3.6$; for integral: base $=$ $94.4,95.9,97.3,98.2 ; \max =214.1,196.5,144.0,194.6 ; 1 / 2 \max _{\max } 64.2$, $-65.1,-63.5,-64.0$; rate $=3.2,2.8,2.8,2.4$ for SAL/EW, SAL/ $\mathrm{LW}, \mathrm{AMPH} / \mathrm{EW}$, and AMPH/LW, respectively).

For Figure 6, there was a significant correlation between spike threshold and spike latency for the SAL group RS and BS neurons that was best fit by a logarithmic regression equation (RS $Y=$ $-54.56+1.78 * \ln (x) ; R^{2}=0.30 ; F_{(1,18)}=8.2 ; p=0.009 ;$ BS $Y=$ $\left.-54.08+1.67 * \ln (\mathrm{x}) ; R^{2}=0.20 ; F_{(1,18)}=4.4 ; p<0.05\right)$.

\section{References}

Bi GQ, Poo MM (1998) Synaptic modifications in cultured hippocampal neurons: dependence on spike timing, synaptic strength, and postsynaptic cell type. J Neurosci 18:10464-10472.

Blaha CD, Yang CR, Floresco SB, Barr AM, Phillips AG (1997) Stimulation of the ventral subiculum of the hippocampus evokes glutamate receptormediated changes in dopamine efflux in the rat nucleus accumbens. Eur J Neurosci 9:902-911.

Caine SB, Humby T, Robbins TW, Everitt BJ (2001) Behavioral effects of psychomotor stimulants in rats with dorsal or ventral subiculum lesions: locomotion, cocaine self-administration, and prepulse inhibition of startle. Behav Neurosci 115:880-894.

Cantrell AR, Scheuer T, Catterall WA (1999) Voltage-dependent neuromodulation of $\mathrm{Na}^{+}$channels by D1-like dopamine receptors in rat hippocampal neurons. J Neurosci 19:5301-5310.

Carr D, Day M, Cantrell AR, Scheuer T, Catterall WA, Surmeier DJ (2003) Transmitter modulation of slow, activity-dependent modulation of sodium channel availability endows neurons with a novel form of cellular plasticity. Neuron 391:793-806.

Castner SA, Goldman-Rakic PS (2003) Amphetamine sensitization of hallucinatory-like behaviors is dependent on prefrontal cortex in nonhuman primates. Biol Psychiatry 54:105-110.

Cooper DC (2002) The significance of action potential bursting in the brain reward circuit. Neurochem Int 41:333-340.

Deisz RA, Fortin G, Zieglgansberger W (1991) Voltage dependence of excitatory postsynaptic potentials of rat neocortical neurons. J Neurophysiol 65:371-382.

Finch DM (1996) Neurophysiology of converging synaptic inputs from the rat prefrontal cortex, amygdala, midline thalamus, and hippocampal formation onto single neurons of the caudate/putamen and nucleus accumbens. Hippocampus 6:495-512.

Floresco SB, Todd CL, Grace AA (2001) Glutamatergic afferents from the hippocampus to the nucleus accumbens regulate activity of ventral tegmental area dopamine neurons. J Neurosci 21:4915-4922.

Gabrieli JDE, Brewer JB Desmond, JE Glover GH (1997) Separate neural bases of two fundamental memory processes in the human medial temporal lobe. Science 276:264-266.

Gasbarri A, Campana E, Pacitti C, Hajdu F, Tombol T (1991) Organization of the projections from the ventral tegmental area of Tsai to the hippocampal formation in the rat. J Hirnforsch 32:429-437.

Gasbarri A, Verney C, Innocenzi R, Campana E, Pacitti C (1994a) Mesolimbic dopaminergic neurons innervating the hippocampal formation in the rat: a combined retrograde tracing and immunohistochemical study. Brain Res 668:71-79.

Gasbarri A, Packard MG, Campana E, Pacitti C (1994b) Anterograde and retrograde tracing of projections from the ventral tegmental area to the hippocampal formation in the rat. Brain Res Bull 33:445-452.

Gasbarri A, Packard MG, Sulli A, Pacitti C, Innocenzi R, Perciavalle V (1996a) The projections of the retrorubral field A8 to the hippocampal formation in the rat. Exp Brain Res 112:244-252.

Gasbarri A, Sulli A, Innocenzi R, Pacitti C, Brioni JD (1996b) Spatial memory impairment induced by lesion of the mesohippocampal dopaminergic system in the rat. Neuroscience 74:1037-1044.

Gonzalez-Burgos G, Barrionuevo G (2001) Voltage-gated sodium channels shape subthreshold EPSPs in layer 5 pyramidal neurons from rat prefrontal cortex. J Neurophysiol 86:1671-1684.

Hampson RE, Hedberg T, Deadwyler SA (2000) Differential information processing by hippocampal and subicular neurons. Ann NY Acad Sci 911:151-165. 
Hitchcott PK, Phillips GD (1997) Amygdala and hippocampus control dissociable aspects of drug-associated conditioned rewards. Psychopharmacology (Berl) 131:187-195.

Hyman SE, Malenka RC (2001) Addiction and the brain: the neurobiology of compulsion and its persistence. Nat Rev Neurosci 2:695-703.

Jones SR, Gainetdinov RR, Wightman RM, Caron MG (1998) Mechanisms of amphetamine action revealed in mice lacking the dopamine transporter. J Neurosci 18:1979-1986.

Jung HY, Staff NP, Spruston N (2001) Action potential bursting in subicular pyramidal neurons is driven by a calcium tail current. J Neurosci 21:3312-3321.

Kepecs A, Wang XJ, Lisman J (2002) Bursting neurons signal input slope. J Neurosci 22:9053-9062.

Laruelle M (2000) The role of endogenous sensitization in the pathophysiology of schizophrenia: implication from recent brain imaging studies. Brain Res Rev 31:371-384.

Legault M, Rompre PP, Wise RA (2000) Chemical stimulation of the ventral hippocampus elevates nucleus accumbens dopamine by activating dopaminergic neurons of the ventral tegmental area. J Neurosci 20:1635-1642.

Li Y, Vartanian AJ, White FJ, Xue CJ, Wolf ME (1997) Effects of the AMPA receptor antagonist NBQX on the development and expression of behavioral sensitization to cocaine and amphetamine. Psychopharmacology (Berl) 134:266-276.

Lieberman JA, Sheitman BB, Kinon BJ (1997) Neurochemical sensitization in the pathophysiology of schizophrenia: deficits and dysfunction in neuronal regulation and plasticity. Neuropsychopharmacology 17:205-229.

Lisman JE (1997) Bursts as a unit of neural information: making unreliable synapses reliable. Trends Neurosci 20:38-43.

Lopes da Silva FH, Arnolds DE, Neijt HC (1984) A functional link between the limbic cortex and ventral striatum: physiology of the subiculum accumbens pathway. Exp Brain Res 55:205-214.

Markram H, Lubke J, Frotscher M, Sakmann B (1997) Regulation of synaptic efficacy by coincidence of postsynaptic APs and EPSPs. Science 275:213-215.

Martin PD, Ono T (2000) Effects of reward anticipation, reward presentation, and spatial parameters on the firing of single neurons recorded in the subiculum and nucleus accumbens of freely moving rats. Behav Brain Res 116:23-38.

Martin PD (2001) Locomotion towards a goal alters the synchronous firing of neurons recorded simultaneously in the subiculum and nucleus accumbens of rats. Behav Brain Res 124:19-28.

Mattia D, Kawasaki H, Avoli M (1997) Repetitive firing and oscillatory activity of pyramidal-like bursting neurons in the rat subiculum. Exp Brain Res 114:507-517.

Miles R, Wong RK (1986) Excitatory synaptic interactions between CA3 neurones in the guinea-pig hippocampus. J Physiol (Lond) 373:397-418.

Murphy CA, Fend M, Russig H, Feldon J (2001) Latent inhibition, but not prepulse inhibition, is reduced during withdrawal from an escalating dosage schedule of amphetamine. Behav Neurosci 115:1247-1256.

Nicola SM, Kombian SB, Malenka RC (1996) Psychostimulants depress excitatory synaptic transmission in the nucleus accumbens via presynaptic D1-like dopamine receptors. J Neurosci 16:1591-1604.

Nishiyama M, Hong K, Mikoshiba K, Poo MM, Kato K (2000) Calcium stores regulate the polarity and input specificity of synaptic modification. Nature 408:584-588.

O’Donnell P, Grace AA (1995) Synaptic interactions among excitatory afferents to nucleus accumbens neurons: hippocampal gating of prefrontal cortical input. J Neurosci 15:3622-3639.

Paulson PE, Camp DM, Robinson TE (1991) Time course of transient behavioral depression and persistent behavioral sensitization in relation to regional brain monoamine concentrations during amphetamine withdrawal in rats. Psychopharmacology (Berl) 103:480-492.

Robinson TE, Becker JB (1986) Enduring changes in brain and behavior produced by chronic amphetamine administration: a review and evaluation of animal models of amphetamine psychosis. Brain Res 396:157-198.

Russig H, Murphy CA, Feldon J (2002) Clozapine and haloperidol reinstate latent inhibition following its disruption during amphetamine withdrawal. Neuropsychopharmacology 26:765-777.

Russig H, Murphy CA, Feldon J (2003) Prepulse inhibition during withdrawal from an escalating dosage schedule of amphetamine. Psychopharmacology (Berl) 169:340-353.

Sharp PE, Green C (1994) Spatial correlates of firing patterns of single cells in the subiculum of the freely moving rat. J Neurosci 14:2339-2356.

Sjostrom PJ, Turrigiano GG, Nelson SB (2001) Rate, timing, and cooperativity jointly determine cortical synaptic plasticity. Neuron 32:1149-1164.

Snider RK, Kabara JF, Roig BR, Bonds AB (1998) Burst firing and modulation of functional connectivity in cat striate cortex. J Neurophysiol 80:730-744.

Staff NP, Jung HY, Thiagarajan T, Yao M, Spruston N (2000) Resting and active properties of pyramidal neurons in subiculum and CA1 of rat hippocampus. J Neurophysiol 84:2398-2408.

Strakowski SM, Sax KW, Setters MJ, Keck PE Jr (1996) Enhanced response to repeated d-amphetamine challenge: evidence for behavioral sensitization in humans. Biol Psychiatry 40:872-880.

Stuart G, Sakmann B (1995) Amplification of EPSPs by axosomatic sodium channels in neocortical pyramidal neurons. Neuron 15:1065-1076.

Swanson LW (1981) A direct projection from Ammon's horn to prefrontal cortex in the rat. Brain Res 217:150-154.

Swanson LW, Cowan WM (1977) An autoradiographic study of the organization of the efferent connections of the hippocampal formation in the rat. J Comp Neurol 172:49-84.

Sweet KL, Neill DB (1999) Amphetamine injections into the nucleus accumbens enhances the reward of stimulation of the subiculum. Ann NY Acad Sci 877:828-830.

Taepavarapruk P, Floresco SB, Phillips AG (2000) Hyperlocomotion and increased dopamine efflux in the rat nucleus accumbens evoked by electrical stimulation of the ventral subiculum: role of ionotropic glutamate and dopamine D1 receptors. Psychopharmacology (Berl) 151:242-251.

Thomson AM, Girdlestone D, West DC (1988) Voltage-dependent currents prolong single-axon postsynaptic potentials in layer III pyramidal neurons in rat neocortical slices. J Neurophysiol 60:1896-1907.

Ujike H (2002) Stimulant-induced psychosis and schizophrenia: the role of sensitization. Curr Psychiatry Rep 4:177-184.

Vorel SR, Liu X, Hayes RJ, Spector JA, Gardner EL (2001) Relapse to cocaine-seeking after hippocampal theta burst stimulation. Science 292:1175-1178.

White FJ, Kalivas PW (1998) Neuroadaptations involved in amphetamine and cocaine addiction. Drug Alcohol Depend 51:141-153.

White JA, Klink R, Alonso A, Kay AR (1998) Noise from voltage-gated ion channels may influence neuronal dynamics in the entorhinal cortex. J Neurophysiol 80:262-269.

Wolf ME (1998) The role of excitatory amino acids in behavioral sensitization to psychomotor stimulants. Prog Neurobiol 54:679-720.

Wolf ME, Dahlin SL, Hu X-T, Xue CJ, White K (1995) Effects of lesions of prefrontal cortex, amygdala, or fornix on behavioral sensitization to amphetamine: comparison with $\mathrm{N}$-methyl-D-aspartate antagonists. Neuroscience 69:417-439.

Zeineh MM, Engel SA, Thompson PM, Bookheimer SY (2003) Dynamics of the hippocampus during encoding and retrieval of face-name pairs. Science. 299:577-580.

Zhang X-F, Hu X-T, White FJ (1998) Whole-cell plasticity in cocaine withdrawal: reduced sodium currents in nucleus accumbens neurons. J Neurosci 18:488-498.

Zhang X-F, Cooper DC, White FJ (2002) Repeated cocaine treatment decreases whole-cell calcium current in rat nucleus accumbens neurons. J Pharmacol Exp Ther 301:1119-1125. 